\title{
Pedagogical Interaction Modeling of EFL Teaching in Polyethnic Groups at Coal Region University
}

\author{
Tatyana Sergeichik ${ }^{1,}$, , and Nina Tunyova ${ }^{1}$ \\ ${ }^{1}$ Kemerovo State University, 650000, 6 Krasnaya st., Kemerovo, Russia
}

\begin{abstract}
Kemerovo State University, the largest institution of higher education in Kuzbass, has a significant contingent of foreign students. The article is devoted to pedagogical interaction modeling of teaching a foreign language in multiethnic groups of the University. The basis for modeling is the textbook of English designed specifically for students of different ethnic groups in order to develop different language skills along with the skills of proper intercultural interaction, successful social adaptation, as well as self-education skills. The content of the textbook is divided into thematic units - modules. Special attention is paid to the text selection as a main communicative and didactic unit of educational content. The practical tasks are classified into three groups. The first group tasks are based on the teaching methods and techniques outside the communicative reality. The second group tasks involve teaching in educational communicative reality. The third group tasks are developed to contribute teaching in natural communicative reality.
\end{abstract}

\section{Introduction}

Kemerovo State University has a contingent of students, the substantial part of which has always traditionally been foreign students. Nowadays, attracting foreign applicants remains one of the main goals of the university. The key objective is to improve the competitiveness of Russian education and therefore increase the non-resource export of Kuzbass, thereby ensuring the sustainable development of Kemerovo region.

University teachers experience an objective need to improve the educational process in a polyethnic student environment. This makes the search and implementation of effective models of pedagogical interaction relevant for the successful teaching in different ethnic groups and training of highly qualified specialists.

This study is devoted to the experience of the educational resources design for the EFL learners. The use of these books in the educational process is aimed to provide students with fundamental knowledge and practise intercultural collaboration skills, favorable social adaptation, as well as the motivation for self-education. In addition to modern variety of educational technologies and methodological ideas [6], the modeling of the educational process takes place on the basis of a textbook, which functions as a frame for organizing the

\footnotetext{
*Corresponding author: 1alli8@mail.ru
} 
activities of students with the teacher, managing the process of foreign language learning and teaching.

\section{Materials and methods}

The research on the problems of EFL teaching at higher educational institutions has been carried out since 2019. In preparing the article the following methods and materials were used: experimentation connected with the content of language education at universities; literature review, questioning and interviewing (22 teachers of foreign languages and 121 students of Kemerovo State University (Kemerovo); analyzing the practice of EFL teaching at Kemerovo State University.

\section{Results and discussion}

Our research deals with designing a textbook as a basis to model teaching a foreign language in multiethnic groups, as well as the experiment of its implementation into teaching.

The textbook is an integral component of the educational process, which acts as a focus for both a teacher and students [4]. Its design considers the multiethnic diversity of students; it is based on a set of approaches and principles that allows take into account the different level of students' language skills.

Among the main textbook's parameters, which determine the vector of EFL teaching at the university and the concept of the textbook's aspects, its content and structure are of primary importance [8].

The content of the educational resource is determined, first of all, by a list of topics in the educational program [1], drawn up on the requirements of the Federal Standard in Higher Education. The core of the whole textbook and its thematic modules is a text which is traditionally considered as a language and speech unit in Russian linguodidactics. The texts selected according to the above principles provide a foreign language content background of the textbook.

The second important parameter of the textbook is its structure. The content is divided into thematic blocks or separate parts concerning different aspects of foreign language learning. Thematic blocks, in turn, are structured in accordance with the author's intention and the chosen methodology.

Thus, the textbook's structure is directed to the modeling of pedagogical interaction in teaching.

As the traditional model of foreign language teaching is based on a set of various language activities - reading, speaking, listening and writing [10], the textbook is designed to ensure their correlation. Namely, understanding, decoding textual information done while listening and reading, serve the basis for generating a text while speaking and writing.

However, we should emphasize one more key parameter of the textbook, that determines the classroom activity, is the target audience. We took it into account when deciding the textbook content, as well as its component parts. Our EFL teaching experience in multiethnic groups shows that the design of a textbook for them, undoubtedly, requires a special methodological approach with the purposeful modeling of pedagogical interaction.

When designing the textbook of English for universities, we primarily paid special attention to the selection of text as a main communicative and didactic unit of educational content. As the crucial task of foreign language teaching at the university is a professional 
thinking development, which is reflected in the foreign language competence, we provided the professional context for the textbook.

In modern teaching techniques, the text serves as the main means of creating an environment to develop foreign language skills [3]. Working with text traditionally accompanies such types of speech activities as reading, listening, speaking, writing. The text is used to develop different aspects of students' foreign language skills in their correlation.

In the textbook of English for non-linguistic undergraduate students, we also added the collection of small texts of different styles and genres: dialogues, quotes of famous people, announcements, resumes, letters, addresses, notes, forecasts, schedules, event programs, cards, menus, advertisements, invitations, etc. We designed special appendices to include some supplementary materials.

It is important that in foreign language classes, the text was considered by students as an object to observe a number of text categories typical of the scientific style. A scientific text with its specific features such as stereotyped form, brevity, clarity, and precision, being an object of pedagogical interaction, acted as a standard for learners when creating their own statements and texts.

As for the grammar-oriented aspects of the texts, they were primarily intended to review the specific grammar constructions by the students. Thus, every module of the textbook included the grammar guide concerned with the linguistic phenomena frequently used in the text.

Within each module of the textbook, a set of exercises and tasks was developed with the use of the topical vocabulary from the basic text regarded as a communicative and didactic unit. The text served as an illustration of a variety of grammar constructions and linguistic phenomena, the essence of which was explained to students in the process of foreign language learning. Undoubtedly, the main element of the structure of a text was the sentence, or phrase, while the minimum didactic unit was a word.

According to the teaching principle of simple to complex, we included three different groups of exercises and tasks to each module of the textbook.

At the initial stage of working with the module, the first group tasks were based on the teaching methods and techniques outside the communicative reality. They focused on studying the topical vocabulary of the module. The pre-text exercises included a lexical minimum on the topic - words and special professional terms necessary for active use in communication.

We also chose the tasks to make comprehension of the basic text easier and draw attention to language difficulties before reading: for example, to compare the equivalents in the Russian and foreign languages. Foreign language examples usually included speech clichés, phrasal verbs, idioms, etc. In a multi-ethnic environment, this type of task served as a platform for intercultural interaction - discussion of the corresponding equivalents in the national languages of students (if any).

Also, module exercises with international topical vocabulary became appropriate in the context of the "dialogue of cultures": the task to find equivalents for the international words in their native language enriched the students' horizons, formed a unique communicative environment, and favored better mutual understanding in multicultural groups.

The second group tasks, involving teaching methods and techniques in educational communicative reality, were offered after the thematic text. They included interactive communicative tasks for all types of language activities.

The second group tasks aimed at developing speaking and writing skills in the form of communicative intentions, included such tasks as "compare", "contrast", "highlight the main idea", "characterize", "provide an assessment", "define the problem" of the text etc. 
As for reading, the basic tasks were concerned with the transformation of the original text, so-called "secondary communication". The tasks involved various forms of text compression (abstracting, annotating), presentation of tabular and graphical information in the form of text, writing a presentation, writing a resume, etc.

The second group tasks were also intended to edit a deformed text and involved such tasks as "fill in the gaps in sentences", "correct (or supplement) statements", "make up phrases from a group of words", etc. Their significance was attached to the fact that a deformed text was used as a link between the reproduced and the produced texts. Reproducing the text, students deepened their knowledge of the key text categories, learnt the specific features of phrase construction, and as a result, improved their textual skills acquired while reading or listening.

The experiment showed that the reproduction of a text in terms of listening practice required from students the skills of copying textual phenomena on the basis of perception. The activities included the writing of a summary, when the student tried to "reconstruct" the given text and its specific features from memory. Such task as to prepare a presentation was intended to develop skills of highlighting the main idea and summarizing the secondary information of the text, accumulating the evidence, conscious using of the vocabulary, applying the knowledge of grammar rules. The presentation skills contributed to the solution of many educational tasks: the text itself as a model along with its content influence the students' consciousness and feelings, guided their professional, cultural and moral ideas, cultivating mental insight culture.

We should emphasize that the development of speaking skills during the experiment was correlated with the practical grammar use. The grammar in the textbook was presented as a means of learning a living language and speech, as well as a basis for students to solve specific communicative and cognitive tasks. Therefore, grammar exercises were offered as part of a set of tasks aimed at learning in educational communicative reality.

The exercises developed at learning in educational communicative reality, also involved asking questions, tasks for organizing discussions and communicative games, including role plays. Such forms of work stimulated cognitive activity, necessary for the educational process productivity.

The discussion assignments provided students with the opportunity to analyze, interpret the text and develop a discussion on its basis. They allowed students to express their own views, evaluate the opinions of classmates, predict the situation development as well as justify it. This form of interaction also served as the basis for the teacher's "installing" of the "dialogue of cultures". This approach, laid down by the textbook's authors, modeled the pedagogical interaction and linguodidactic intentions of a teacher.

In this respect, when designing communicative tasks, we regarded discussion not only as a form of educational activities, but also as a pedagogical method of education [2]. Therefore, the discussion topics included ethno-related aspects of different problems, and were directed to ensure mutual respect among students from different ethnic groups.

The discussion tasks of the textbook of English provided an ethno-oriented component that promotes the socio-cultural awareness of students concerning the cultural and national features of their foreign groupmates. They were aimed at eliminating incidents associated with prejudices, xenophobia and nationalism in the multiethnic environment of the university. Also, the questions raising the problems of cultural and national features along with specific attributes of international communication, ensured the support and development of suitable cultural ideas and beliefs regarding students of different ethnic groups.

In addition, the experiment confirmed that the tasks and exercises of the second group stimulated students' speaking activity - both reproductive and productive, and therefore were difficult to complete. The complexity of the assignments revealed a necessity to 
support these tasks with appropriate samples. It was reasonable to place those samples within the assignment instruction.

The third group tasks were developed to contribute to the teaching methods and techniques in natural communicative reality. The tasks presented more significant difficulty for students, as they involved students' productive activity, and even their creativity. By making up their own text, students practiced their skill to use the theory freely.

The task to make up a text (oral and written) in natural communicative reality was the final part of each thematic module of the textbook. The oral practice implied assignments to prepare individual, pair or group projects, for example, using IT - dynamic or interactive thematic presentations, video reports, digital stories, interviews or sociological surveys [7], sometimes with the participation of foreign friends via the Internet. We offered students different web-services and apps to do it (Genial.ly, Prezi, Quizzes, Factile etc.) [9]. All these digital tools were integrated in classroom learning and were familiar to students [5]. Besides, students succeeded to develop the essential digital skills.

Presentation of an individual project in a foreign language was associated with a substantial independent activity of students, including both reproductive and productive forms of working with a foreign language text. The undoubted advantage of individual project work was the correspondence of its content to the student's personal interests and preferences: it encouraged learning as well as provides enthusiasm in the language environment.

The productive tasks for multiethnic student groups provided an ethnocultural component with a powerful educational potential. Presentations, reports and other types of productive activities covered such topics as biography and achievements of an outstanding national scientist, specific features of national higher education, national features of employment, problems of ecology in their native country, peculiarities of using IT by different social (age, gender) groups in their country, etc. The process of exchanging knowledge about national cultures (history, geography, ecology, education, science, etc.) among students who were in contact within the framework of educational activities at the university contributed to the cross-cultural literacy, recognition by the participants of their cultural identity, the creation of a favorable ethno-oriented university environment.

The collaboration tasks designed to learn cooperation, in addition to developing the foreign text production skills, had a number of educational functions. Cooperation ensured a respectful mutual attitude among students, manifested in endurance and tact, proper interpersonal interaction, ethnic tolerance.

Collaboration, initiated by the tasks of the textbook, gave students the opportunity to learn how to feel comfortable and confident in a natural professional environment, formed by groupmates during the period of study at the university.

Certainly, many students had difficulties doing some tasks from the second and third groups. It was particularly true for the students with poor academic performance, as well as for foreign students, because they needed to deal with the significant foreign language vocabulary and use grammar freely in independent speaking. Therefore, the textbook of English was provided with a functional appendix, where instructions, memos, models, sample texts of different formats were presented.

\section{Conclusion}

The combination of the above listed approaches contributed to the design of a modern textbook of English for universities considering the multiethnic diversity of students. This allowed the different level of students' language skills, as well as maintain interest and increase the motivation of students to the language learning due to its content, and structure. 
The textbook as a basis for modeling of foreign language teaching process in multiethnic groups contributed to the foreign language communicative competence development, which was revealed in the ability and willingness to carry out foreign language communication in oral and written forms.

In a competence-based approach, the development of the textbook of English for multiethnic groups solved a number of problems related to modeling the learning environment, which ensured students the skills of extracting, processing, storing information and further communication.

The essential result of implementing with ethno-oriented textbooks of English was the enrichment of the axiological component of the student's personality: strengthening their character and behavior, guiding their moral principles, development of cultural values. These qualities and skills are required by all forms of employment, and contribute to the sustainable development of the coal mining region.

\section{Acknowledgement}

The reported study was funded by RFBR according to the research project № 19-01300805 .

\section{References}

1. L.V. Almjashova, O.V. Mytyakina, G.A. Jdanova, Life Science Journal, 11:10s, 209210 (2014)

2. A.G. Bermus, Culture and Education: Social Transformations and Multicultural Communication, 1, 179-187 (2019) DOI: 10.22363/09669-2019-179-187 (2019)

3. G. Chistyakova, E. Bondareva, K. Demidenko, E. Podgornaya, O. Kadnikova, E3S Web Conf. 15, 04010 (2017)

4. E.V. Dzyuba, DETP, 437, 256-261 (2020)

5. R. Islamov, O. Greenwald, N. Tunyova, E3S Web Conf. 174, 04042 (2020)

6. V.V. Kotlyarova, A. G. Bermus, AISC, 1100, 256-266 (2020)

7. A. Perevalova, A. Resenchuk, N. Tunyova, E3S Web Conf. 174, 04051 (2020)

8. D. V. Sedykh, European Journal of Natural History, 2, 78-80 (2018)

9. N. Tunyova, E3S Web Conf. 105, 04041 (2019)

10. S.A. Zolotareva, M.V. Mezhova, Competence and Semiotic Approach. European Researcher, 3-2 (71), 614-620 (2014) 